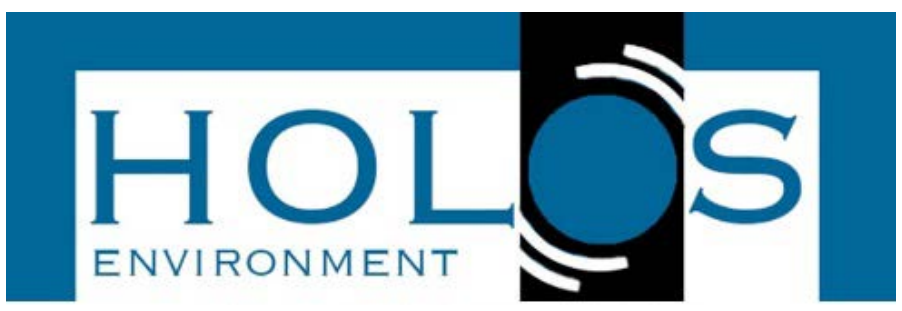

\title{
BIOMASSAS BRASILEIRAS APLICADAS À REMOÇÃO DE URÂNIO DE DRENAGEM ÁCIDA DE MINAS POR PROCESSOS DE BIOSSORÇÃO
}

\author{
BRAZILIAN BIOMASS APPLIED TO URANIUM REMOVAL FROM ACID MINE \\ DRAINAGE BY BIOSORPTION PROCESS
}

\author{
Milena Rodrigues Boniolo; ${ }^{1}$ Lauren Nozomi Marques Yabuki²; Daniela Andresa Mortari \\ Amauri Antonio Menegário1; Marcelo Loureiro Garcia ${ }^{2}$
}

Artigo recebido em: 15/08/2017 e aceito para publicação em: 07/11/2017.

DOI: http://dx.doi.org/10.14295/holos.v17i1.12214

\begin{abstract}
Resumo: Este trabalho teve como objetivo avaliar a redução da concentração de urânio em área de drenagem ácida de mina. O Brasil possui a sexta maior reserva de urânio do mundo e há grande quantidade de rejeitos acumulados contendo íons metálicos, semimetálicos e radiotóxicos. O método utilizado neste estudo para remover urânio foi a biossorção mediante a aplicação de biomassas brasileiras. Os efluentes aplicados foram coletados na mina Osamu Utsumi, que pertence às Indústrias Nucleares do Brasil e os biossorventes empregados nos ensaios foram cascas de banana, semente de moringa e borra de café. A decomposição térmica, a porosimetria de adsorção de nitrogênio e a microscopia eletrônica de varredura (MEV) foram realizadas para caracterizar fisicamente os biossorventes. A partir dos resultados obtidos, observou-se que os biossorventes com maior área de superfície e maior volume de poros resultaram em maiores valores de eficiência de remoção, com uma ordem crescente desses parâmetros: cascas de banana < borra de café < sementes de moringa. Considerando as amostras de efluentes com concentração de urânio de $6 \mathrm{mg} \mathrm{L}^{-1}$, as sementes de moringa apresentaram remoção de aproximadamente $87 \%$, enquanto a borra de café e cascas de banana apresentaram remoção de 74 e 56\%, respectivamente.
\end{abstract}

Palavras-chave: Adsorção de urânio. Drenagem ácida de mina. Casca de banana. Semente de moringa. Borra de café.

Abstract: This work aimed to evaluate the uranium concentration reduction in acid mine drainage. Brazil owns the sixth biggest uranium reserve in the world and there is large amount of accumulated tailings containing metallic, semi-metallic and radiotoxic ions. The method used in this study to remove uranium was biosorption by applying Brazilian biomass. The applied effluents were collected at the Osamu Utsaumi mine, which belongs to Industries Nucleares of Brazil and the biosorbents used in the tests were banana peel, moringa seed and spent coffee ground. Thermal decomposition, nitrogen adsorption porosimetry and scanning electron microscopy (SEM) were performed in order to characterize the biosorbents physically. From the results, it was observed that the biosorbents with a higher surface area and higher pore volume resulted in higher removal efficiency values, with an ascending order of these parameters: banana peels

${ }^{1}$ Universidade Estadual Paulista (UNESP), Centro de Estudos Ambientais, Rio Claro. E-mails: (milenaboniolo@yahoo.com.br, amenega@rc.unesp.br)

2 Universidade Estadual Paulista (UNESP), Instituto de Geociências e Ciências Exatas, Rio Claro. E-mails: (lauren.yabuki@gmail.com, mlgarcia@rc.unesp.br)

3 Universidade de São Paulo (USP), Departamento de Engenharia Mecânica, São Carlos. E-mail: danielamortari@yahoo.com.br 
<spent coffee ground <moringa seeds. Considering the effluent samples with uranium concentration of $6 \mathrm{mg}$ $\mathrm{L}^{-1}$, the moringa seeds presented removal of approximately $87 \%$, while the spent coffee grounds and banana peels presented removal of 74 and $56 \%$, respectively.

Keywords: Uranium adsorption. Acid Mine Drainage. Banana peel. Moringa seed. Spent coffee ground.

\section{NTRODUÇÃO}

Devido às grandes preocupações em relação ao fornecimento de energia proveniente de combustíveis fósseis e ao aumento de emissões de gases de efeito estufa, a procura por métodos alternativos de geração energia conduziram ao crescimento da procura de energia nuclear ${ }^{1}$.

O urânio é conhecido como a base da indústria nuclear. No entanto, a atividade mineradora e o processamento de urânio geram significativos impactos na qualidade dos diferentes compartimentos ambientais, além das áreas contaminadas existentes que necessitam de tratamento e adequação ambiental. De acordo com resultados apresentados na literatura, a concentração de urânio em águas residuárias pode chegar até $15 \mathrm{mg} \mathrm{L}^{-1}$ e os níveis admissíveis de descarga de urânio variam entre 0,1 e 0,5 $\mathrm{mg} \mathrm{L}^{-1}$. Desta forma, o desenvolvimento de novas tecnologias de remoção é necessário para evitar ou amenizar os impactos ambientais causados devido ao uso dessa fonte de energia ${ }^{1,2}$.

Um dos problemas de destaque tem sido a presença de urânio na drenagem ácida de minas (DAM), que surge a partir da oxidação de minerais sulfetados na presença de água e oxigênio, favorecendo assim a formação do ácido sulfúrico que, ao reduzir o pH do meio, possibilita a dissolução de íons metálicos ${ }^{3}$. Estas águas devem ser tratadas antes de serem descartadas no meio ambiente, uma vez que baixos valores de $\mathrm{pH}$ frente a este cenário apresentam elevado potencial poluidor necessitando, portanto, de manejo e gestão eficientes.

Áreas afetadas por contaminação de íons metálicos são comumente tratadas por meio de processos físico-químicos como a precipitação química associada à sedimentação e filtração. No entanto, quando existe grande volume de efluente com íons metálicos a baixas concentrações, este tipo de tratamento pode ser ineficiente, sendo necessária uma etapa posterior denominada tratamento terciário ou polimento que engloba diversos procedimentos dentre os quais se encontram os processos relacionados à adsorção. 
Tendo em vista este cenário torna-se necessário o desenvolvimento de tecnologias e alternativas de baixo custo a fim de mitigar e remediar este problema. Pesquisas envolvendo o uso de materiais naturais na remoção de íons indesejados, como a biossorção, têm sido amplamente realizadas e se mostrado eficiente no tratamento das águas residuárias ${ }^{2,4-6}$. De acordo com a literatura, diversos materiais tem sido empegados com sucesso para a remediação de íons metálicos em efluentes como, por exemplo, bactérias, fungos, algas, leveduras, resíduos agrícolas, entre outros ${ }^{2}$. Algumas das principais vantagens no uso destes materiais referem-se ao fato de que as biomassas utilizadas ainda não apresentam valor comercial, uma vez que na maior parte dos casos são subprodutos de um processo industrial ou ainda considerados resíduos, devido ao grande volume gerado nos setores alimentício e agroindustrial. ${ }^{7-9}$. Neste contexto, é interessante a valorização de resíduos locais e de alta disponibilidade para aplicações diversas. Neste trabalho três biomassas - casca de banana, sementes de moringa e borra de café, foram empregadas como biossorventes no tratamento de urânio em efluentes.

A casca de banana é amplamente investigada para adsorção de metais e há vários trabalhos reportando suas características e as vantagens para aplicação ${ }^{10,11}$. Sua estrutura apresenta textura com alta porosidade, constituída por celulose, hemicelulose, lignina, pectinas, amidos e proteínas ${ }^{10}$. Além de ser amplamente consumida no Brasil, a banana ocupa a quarta posição na lista de produtos alimentares mais produzidos mundialmente precedidos pelo arroz, trigo e milho. Adicionalmente a esse fato, aproximadamente $40 \%$ do peso da fruta, torna-se resíduo devido ao descarte da casca da banana ${ }^{10}$.

O café é uma das bebidas mais populares e consumidas no mundo e o aumento na taxa de consumo continua a crescer aproximadamente 2,4\% por ano, atingindo 9 milhões de toneladas em 2014 ${ }^{12-15}$. Neste contexto, a geração de resíduos provenientes do processamento de café é estimado em 8 milhões de toneladas por ano e grande parte é descartada, contando apenas com algumas aplicações, como por exemplo em queimadores para co-geração de energia e cultivo de $\operatorname{cogumelos}^{13}$. No entanto, a utilização não é significativa frente às quantidades de resíduos produzidos e há a carência de metodologias para o uso eficiente dessa biomassa. O manejo inadequado deste resíduo pode causar sérios problemas ambientais devido ao alto consumo de oxigênio durante a decomposição do conteúdo orgânico, além da liberação de cafeína residual, tanino e polifenóis ${ }^{13-15}$. O resíduo de café, por possuir vários grupos funcionais, apresenta 
um grande potencial na adsorção poluentes tais como metais pesados, corantes entre outros componentes em águas residuárias ${ }^{16-19}$.

A moringa é uma planta tropical bem conhecida devido as suas características nutricionais únicas e a presença de componentes ativos coagulantes que podem ser amplamente utilizada em tratamentos ambientais como, por exemplo, purificação de água para consumo e águas residuárias provenientes de diversos processos ${ }^{18-23}$. Quase todas as partes desta planta são usadas em diferentes finalidades. Apesar do grande potencial do uso desta biomassa em tratamentos de efluentes industriais, poucos estudos envolvendo o uso de moringa oleífera como biossorvente na remoção de metais pesados são reportados na literatura ${ }^{24}$.

Este estudo teve como objetivo avaliar a redução da concentração de urânio em amostras de drenagem ácida de minas por meio da biossorção com cascas de banana, borra de café e sementes de moringa. Os biossorventes foram classificados e avaliados em relação as suas propriedades físicas a fim de compreender o quanto a caracterização física pode auxiliar na otimização de estudos de biossorção de urânio em amostras de drenagem ácida de minas, além de agregar valor a essas biomassas. Ensaios de decomposição térmica, porosimetria de adsorção de nitrogênio e microscopia eletrônica de varredura foram efetuados de modo a caracterizar fisicamente os biossorventes citados.

\section{METODOLOGIA}

\subsection{Materiais e métodos de preparo}

As biomassas utilizadas como biossorventes neste estudo foram casca de banana, borra de café e sementes de moringa.

As cascas de bananas utilizadas (Musa cavendishi) foram compradas no comércio disponível na região e, após o consumo das frutas, as cascas foram cortadas longitudinalmente e dispostas em bandejas de material plástico para secagem. A borra de café (Coffea arabica L.), após passar pelo processo de extração em máquina, foi coletada e armazenada em plásticos hermeticamente fechados. As sementes de moringa utilizadas (Moringa oleífera Lam) foram coletadas no viveiro de mudas Pontal Verde, localizado em Narandiba - SP. As sementes foram separadas em quatro lotes com 1000 sementes cada e mantidas em dessecador para ensaios posteriores. 
Todas as biomassas foram desidratadas em estufa com circulação forçada de ar (Fanem Mod. $320 \mathrm{SE}$ ), no intervalo de temperatura de $35-40^{\circ} \mathrm{C}$ por aproximadamente $12 \mathrm{~h}$. Este foi o tempo necessário até a obtenção de peso constante para massa de amostra igual de $500 \mathrm{~g}$. Em seguida, as cascas de banana e sementes de moringa foram trituradas no moedor (Tecnal Mod. TE 633) e peneiradas com auxílio de peneiras granulométricas (Bronzinox) até que atingissem a granulometria média de $250 \mu \mathrm{m}$. A borra de café, material mais fino, foi moída com o uso de moinho analítico (IKA mod A11) capacidade de $80 \mathrm{~mL}$ e posteriormente peneiradas para compor a faixa granulométrica desejada. Os biossorventes foram armazenados para estudos posteriores em frascos plásticos dentro de dessecador ${ }^{25}$.

\subsection{Análise Termogravimétrica}

Para verificar a temperatura na qual tem início a degradação de cada biomassa, foram realizados experimentos termogravimétricos em um equipamento Shimadzu TGA51. Em um suporte de alumina foram introduzidos 7,0 $\pm 0,5 \mathrm{mg}$ de amostra no forno da balança termogravimétrica e a programação foi ajustada para que a temperatura variasse da temperatura ambiente até $900{ }^{\circ} \mathrm{C}$. Para todos os materiais a razão de aquecimento aplicada foi de $10^{\circ} \mathrm{C} \mathrm{min}{ }^{-1}$. O gás de arraste utilizado foi de ar sintético com vazão igual a $100 \mathrm{~mL} \mathrm{~min}{ }^{-1}$. O software TA-60WS Collection Monitor foi utilizado em todos os experimentos, para fazer a programação e aquisição de dados.

As curvas resultantes desta técnica analítica fornecem a variação da massa à medida que a amostra é submetida ao aumento controlado de temperatura. No processo de aquecimento há a pesagem contínua da amostra e a partir da variação da massa pode-se concluir sobre a estabilidade térmica e os eventos de decomposição característicos de cada amostra.

\subsection{Porosimetria de adsorção de nitrogênio}

Os parâmetros físicos avaliados das biomassas foram área superficial (método Brunauer, Emmett e Teller - BET) $\left(S_{P} \mathrm{~m}^{2} \mathrm{~g}^{-1}\right)$, volume de poros $\left(\mathrm{V}_{\mathrm{P}} \mathrm{cm}^{3} \mathrm{~g}^{-1}\right)$ e diâmetro de

poros $\left(D_{P} \AA\right)$, medidos via adsorção de nitrogênio $N_{2}(g)$ no analisador Acelerated Surface Area ADN Porosimetry System 2020 (ASAP) Micromeritics a $77 \mathrm{~K}\left(-196{ }^{\circ} \mathrm{C}\right)$. 
Amostras de 0,500 $\mathrm{g}$ foram utilizadas. Antes dos ensaios, as amostras foram secas em estufa por $12 \mathrm{~h}$ e passaram pelo processo de degaseificação (DEGAS), no qual há retirada dos gases adsorvidos na superfície porosa das amostras. Esta etapa é realizada no próprio porosímetro. Inicialmente fez-se o aquecimento a uma razão de aquecimento de $10^{\circ} \mathrm{C}$ min $^{-1}$ até $80^{\circ} \mathrm{C}$. Em seguida, foi feita a evacuação da amostra (vácuo restrito) a uma taxa de $5 \mathrm{mmHg} \mathrm{s}^{-1}$ até $5 \mathrm{mmHg}$. Após essa etapa, a programação foi ajustada para vácuo não restrito aplicando-se a mesma taxa de $5 \mathrm{mmHg} \mathrm{s}^{-1}$ até que atingisse $10 \mu \mathrm{mHg}$, permanecendo nestas condições por $12 \mathrm{~h}$.

Após estas duas etapas de preparação, a porosidade do material foi analisada por meio da adsorção de nitrogênio. Iniciou-se a evacuação da amostra (vácuo restrito) a uma taxa de $5 \mathrm{mmHg} \mathrm{s}^{-1}$ até $5 \mathrm{mmHg}$; mudou-se para vácuo não restrito na mesma taxa até 10 $\mu \mathrm{mHg}$, ficando nestas condições por 6 min. Em seguida, aplicou-se então uma programação para 37 pontos de $P / P_{0}$ - razão entre pressão aplicada $(P)$ e pressão de vapor de saturação do adsorvido $\left(P_{0}\right)$, neste caso o $N_{2}$ - sendo 24 pontos na adsorção e 13 pontos na dessorção.

As análises foram feitas em triplicata para todas as biomassas pelo laboratório do Departamento de Engenharia Mecânica da Escola de Engenharia de São Carlos - EESC da Universidade São Paulo (USP).

\subsection{Microscopia eletrônica de varredura}

Os biossorventes, após o preparo, foram mantidos em dessecador por $24 \mathrm{~h}$ antes da análise no microscópio eletrônico de varredura (LEO 440i) equipado com espectrômetro de energia dispersiva (EDS) de modo a observar a composição elementar da amostra. Trata-se de uma análise semi-quantitativa (onde não há utilização de padrões com concentrações conhecidas dos elementos a serem analisados) realizada em diferentes porções da amostra.

A fim de obter informações a respeito da morfologia do material, uma pequena porção da amostra foi montada no suporte porta amostras do microscópio ("stub") com auxílio de fita dupla face para as análises que foram realizadas no Centro de Ciência e Tecnologia de Materiais - CCTM - IPEN/ SP. 


\subsection{Ensaios de adsorção com amostras do efluente}

Para os ensaios de adsorção aplicando-se os efluentes reais os materiais foram coletados durante três visitas técnicas na Usina de Tratamento de Minérios Osamu Utsumi da INB. Em 2013, as visitas bem como a coleta de amostras do efluente foram realizadas nos meses de fevereiro (Amostra 1) e novembro (Amostra 2). Já em 2014, a campanha para coleta foi realizada em julho (Amostra 3).

Após coleta, as amostras foram mantidas sob refrigeração a $5{ }^{\circ} \mathrm{C}$ para posterior análise em laboratório, sendo efetuados três ensaios em triplicata.

Alíquotas de $10 \mathrm{~mL}$ de amostra foram adicionadas em tubos de $50 \mathrm{~mL}$ com 0,1 g dos biossorventes estudados. Os frascos foram colocados sob agitação de 60 rpm por 45 minutos (Labnet Orbit 300) e deixados em repouso por 15 min para sedimentação das partículas de biomassa carregadas com íons de urânio. Após esta etapa, o sobrenadante foi separado com auxílio de seringas dosadoras (Injex) e filtros seringa de acetato de celulose de 0,45 $\mu \mathrm{m}$ (Sartorius). Os ensaios foram realizados a temperatura de $25 \pm 2{ }^{\circ} \mathrm{C}$.

As amostras referem-se à drenagem ácida de minas (DAM) antes dos tratamentos empregados atualmente na UTM Osamu Utsumi, ou seja, sem ajuste de pH e/ou adição de qualquer produto químico. Para melhor visualização, na Tabela 1 são apresentadas as condições experimentais empregadas para os testes de adsorção com os biossorventes cascas de banana, sementes de moringa e borra de café em amostra de efluentes reais.

Tabela 1- Condições experimentais empregadas para os testes com os biossorventes cascas de banana, sementes de moringa e borra de café em amostra de efluente real

\begin{tabular}{cc}
\hline Variáveis & Valores médios \\
\hline Tamanho do biossorvente $(\mu \mathrm{m})$ & 250 \\
Temperatura $\left({ }^{\circ} \mathrm{C}\right)$ & 25 \\
Massa do biossorvente $(\mathrm{g})$ & 0,1 \\
Tempo de equilíbrio $(\mathrm{min})$ & 45 \\
Tempo para sedimentação $(\mathrm{min})$ & 15 \\
Velocidade de agitação $(\mathrm{rpm})$ & 60 \\
\hline
\end{tabular}

\subsection{Porcentagem de remoção (E)}

A fim de avaliar as respostas dos ensaios de adsorção em batelada, a 
porcentagem de remoção foi calculada a partir da Equação 1:

$$
\text { Remoção }(\%)=\frac{C_{0}-C_{f}}{C_{0}} \times 100
$$

sendo $\mathrm{C}_{0}\left(\mathrm{mg} \mathrm{L}^{-1}\right)$ a concentração inicial da solução de urânio colocada em contato com as biomassas e $\mathrm{C}_{f}\left(\mathrm{mg} \mathrm{L}^{-1}\right)$ a concentração do urânio após o ensaio em batelada.

\subsection{Espectrometria de emissão óptica por plasma acoplado indutivamente (ICP-OES)}

Após os ensaios em batelada, o sobrenadante foi acidificado a $2 \%$ com ácido nítrico e as amostras foram analisadas por ICP-OES (Thermo Scientific, modelo ICAP 6000 Series). A curva analítica foi construída a partir de soluções padrões mono elementar com a mesma concentração de ácido presente na amostra. As condições de operação do equipamento são apresentadas na Tabela 2. Os limites de detecção (LD) e quantificação (LQ) foram calculados a partir da leitura do desvio padrão de amostras sem a adição do íon metálico de interesse; sendo o LD igual a três vezes o valor do desvio padrão medido e o LQ igual a dez vezes este valor.

\begin{tabular}{cc} 
Tabela 2 - Condições de operação durante as análises no ICP-OES \\
\hline Taxa de fluxo da bomba & $0 \mathrm{rpm}$ \\
Taxa de análise da bomba & $15 \mathrm{rpm}$ \\
Tempo de estabilização da bomba & $5 \mathrm{~s}$ \\
Tipo/modelo de tubo & Tygon Orange/White \\
Potência RF & $1150 \mathrm{~W}$ \\
Fluxo do gás auxiliar & $0,5 \mathrm{~L} \cdot \mathrm{min}^{-1}$ \\
Vazão do gás de nebulização & $0,5 \mathrm{~L} \cdot \mathrm{min}^{-1}$
\end{tabular}

Fonte: Software iTEVA do ICP-OES (iCAP 6000 Series) (2015)

\section{RESULTADOS E DISCUSSÃO}

A Figura 1 mostra as curvas termogravimétricas (TG) e suas curvas derivadas (DTG) obtidas durante a decomposição térmica da casca de banana, sementes de moringa e borra de café, aplicando-se a razão de aquecimento de $10{ }^{\circ} \mathrm{C} \mathrm{min}^{-1} \mathrm{em}$ atmosfera de ar sintético. 
Figura 1- Curvas TG e DTG da decomposição térmica dos biossorventes (a) casca de banana, (b) sementes de moringa e (c) borra de café

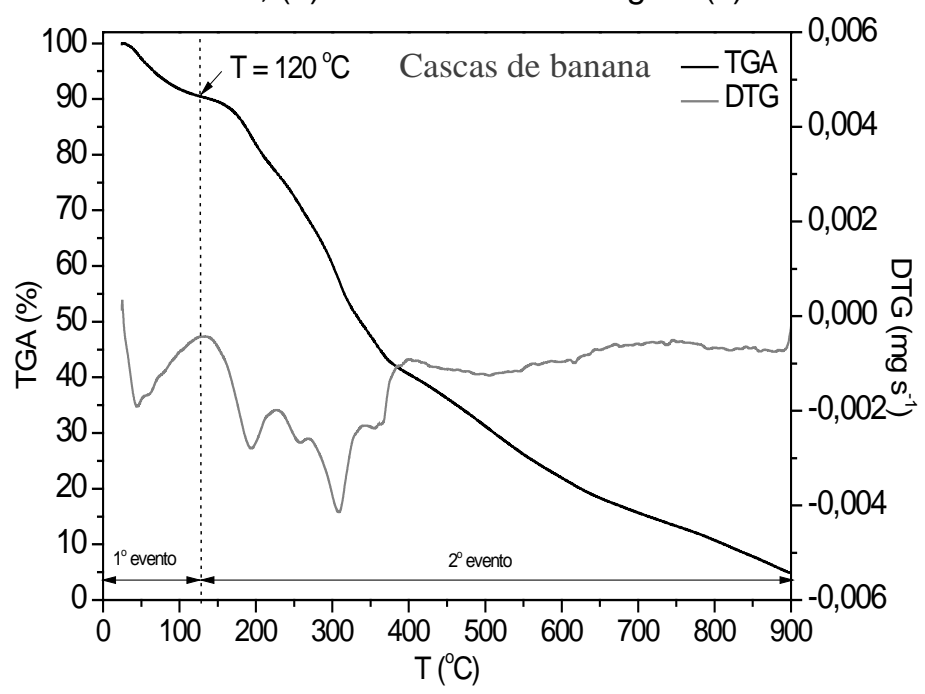

(a)

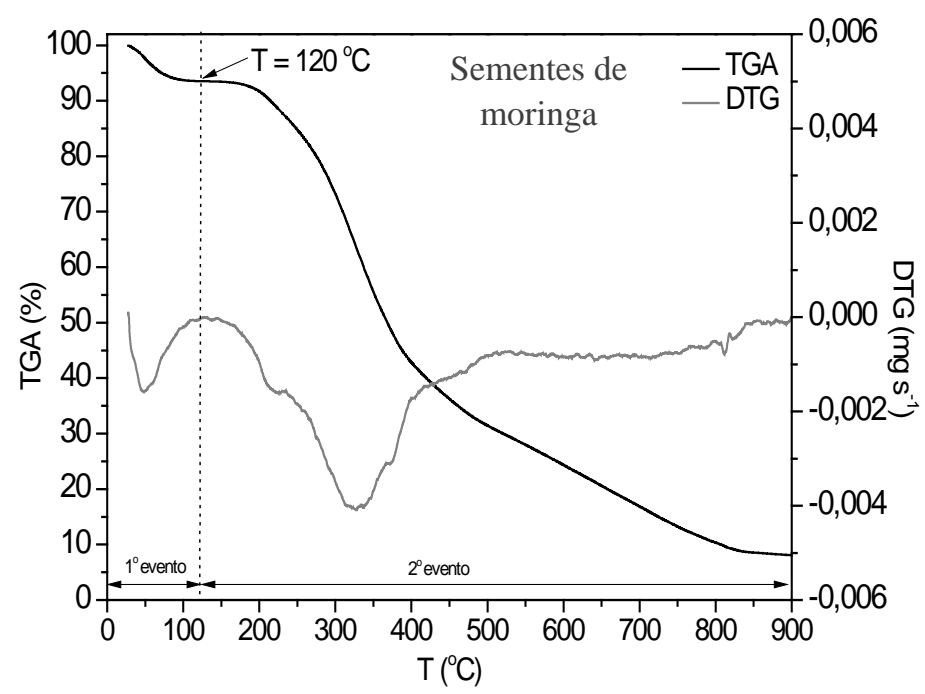

(b)

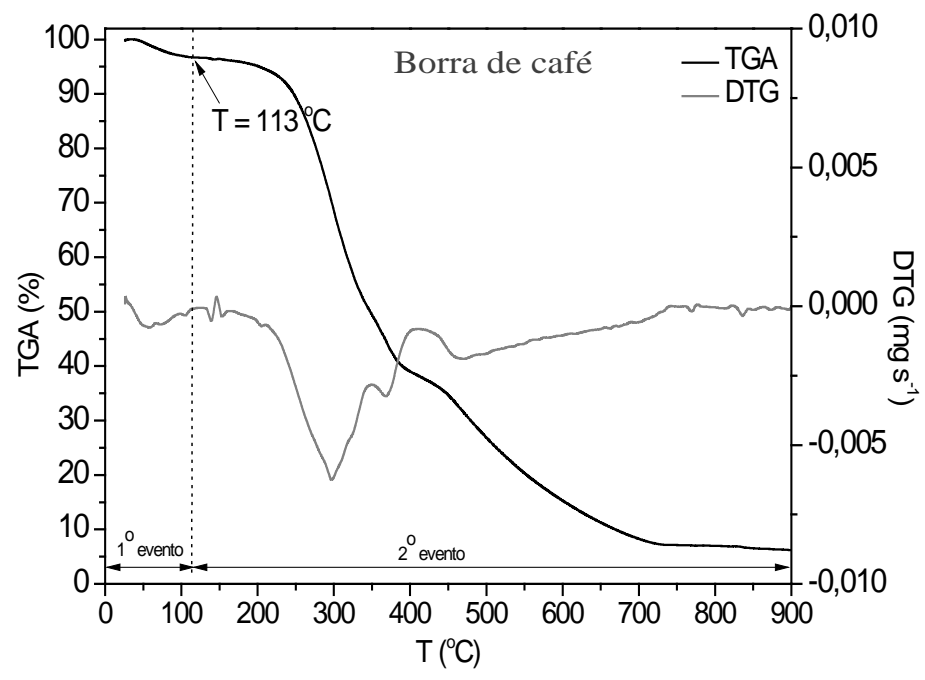

(c) 
Embora as biomassas possam diferir em aspecto umas das outras, elas possuem em comum o fato de serem constituídas por três componentes principais: celulose, hemicelulose e lignina ${ }^{26}$. Portanto, o comportamento destas amostras frente à análise térmica apresentam perfis de decomposição similares, variando apenas devido às diferentes proporções de cada constituinte nos diferentes biossorventes.

De acordo com as curvas TG/DTG obtidas nesse estudo, observa-se que em aproximadamente $100{ }^{\circ} \mathrm{C}$ há um patamar, ou seja, uma região em que não há perda de massa com o aumento da temperatura. Esse patamar indica o fim de um estágio e início de outro. No caso, é referente ao fim da perda de umidade (que é um evento endotérmico) e início da decomposição do componente volátil da amostra (evento exotérmico). Apesar de este patamar estar bem claro para as curvas da semente de moringa e borra de café, ele não é claramente distinguível para a casca de banana. No entanto, ele pode ser visualizado mais claramente na curva derivada DTG. Neste caso, as mudanças de eventos são claramente distinguidas pela mudança de inflexão das curvas. De acordo com a literatura, vários autores reportam que a decomposição térmica do material volátil se inicia a temperaturas acima de $160^{\circ} \mathrm{C}$ e, em temperaturas inferiores a $160^{\circ} \mathrm{C}$, somente o evento relacionado à perda de umidade é reportado ${ }^{27-32}$.

A análise termogravimétrica foi realizada a fim de encontrar a temperatura na qual tem início à degradação da matéria prima dos supracitados biossorventes. Este resultado é essencial para definir as temperaturas ideais aplicadas durante os testes de adsorção de nitrogênio para avaliar a porosidade e garantir a integridade das biomassas de forma a não serem destrutivas. De acordo com as curvas apresentadas na Figura 1, as temperaturas que se iniciam o processo de decomposição são $120{ }^{\circ} \mathrm{C}$ para a casca de banana e sementes de moringa e, $113^{\circ} \mathrm{C}$ para a barra de café. De forma geral, para as três biomassas, até a temperatura de $120^{\circ} \mathrm{C}$ houve perda de umidade; no intervalo de 200 a $400^{\circ} \mathrm{C}$ teve início a degradação dos voláteis: a hemicelulose é a que pirolisa primeiro por ser um componente presente nas biomassas que se degrada mais facilmente em temperaturas mais baixas, seguida da celulose com perda de massa entre 300 e $400^{\circ} \mathrm{C}$, já a lignina, a depender da rampa de temperatura aplicada pode persistir até 700 ${ }^{\circ} \mathrm{C}^{33}$. Esse comportamento frente ao aumento da temperatura está relacionado à estrutura química de cada componente citado. A hemicelulose é constituída por vários sacarídeos que são estruturas amorfas, ricas em ramificações que são facilmente degradadas termicamente. Já a celulose consiste em longos polímeros de glucose, sem ramificações, que consiste em uma estrutura ordenada e forte, com alta estabilidade térmica. A lignina, 
por sua vez, é constituída por anéis aromáticos, com muitas ramificações, que faz com que a decomposição térmica ocorra em um range extenso de temperatura ${ }^{27}$.

$\mathrm{Na}$ Tabela 3 são apresentadas as médias dos resultados de área superficial BET $\left(S_{P}\right)$, volume de poros $\left(V_{P}\right)$ e diâmetro de poros $\left(D_{P}\right)$ dos ensaios de porosimetria de adsorção de nitrogênio.

Tabela 3- Parâmetros físicos médios obtidos pela análise de porosimetria de adsorção de $N_{2}$ para as sementes de moringa, cascas de banana e borra de café

\begin{tabular}{cccc}
\hline Biossorvente & $\begin{array}{c}\mathrm{S}_{\mathrm{P}} \\
\left(\mathrm{m}^{2} \cdot \mathrm{g}^{-1}\right)\end{array}$ & $\begin{array}{c}\mathrm{V}_{\mathrm{P}} \\
\left(\mathrm{cm}^{3} \cdot \mathrm{g}^{-1}\right)\end{array}$ & $\begin{array}{c}\mathrm{D}_{\mathrm{P}} \\
(\AA)\end{array}$ \\
\hline Cascas de Banana & 0,17 & $3,51 \times 10^{-4}$ & 133,55 \\
Sementes de Moringa & 0,56 & $1,48 \times 10^{-3}$ & 131,75 \\
Borra de café & 0,30 & $8,84 \times 10^{-4}$ & 155,64 \\
\hline
\end{tabular}

De acordo com os resultados apresentados na Tabela 3, observou-se que a área superficial BET das sementes de moringa $\left(0,5549 \mathrm{~m}^{2} \mathrm{~g}^{-1}\right)$ é aproximadamente três vezes maior que o valor encontrado para as cascas de banana $\left(0,1657 \mathrm{~m}^{2} \mathrm{~g}^{-1}\right)$, e o dobro da área superficial da borra de café $\left(0,2961 \mathrm{~m}^{2} \mathrm{~g}^{-1}\right)$. $\mathrm{O}$ volume de poros nas sementes de moringa é uma ordem de grandeza maior que o da banana e da borra de café e a diferença entre o diâmetro dos poros dos três biossorventes não se mostrou significativa, apresentando valor igual a 131,752 ( $\AA$ ) para as sementes de moringa, 133,551 ( $\AA$ ) para as cascas de banana e 155,637 ( $\AA$ ) para a borra de café.

A partir dos resultados obtidos, observa-se que as sementes de moringa apresentam características físicas mais relevantes para serem utilizadas como biossorvente, ou seja, maior área de superfície específica e maior porosidade quando comparada às cascas de banana e a borra de café. Ao analisar as biomassas, baseandose apenas na caracterização física, sugere-se a moringa como sendo o biossorvente com maior viabilidade para aplicação seguida pela borra de café e cascas de banana. Nos estudos publicados anteriormente ${ }^{34}$, esses dados da caracterização física das biomassas foram comparados com carvão ativado, argilas e turfa, obtendo maiores potenciais de remoção (baseados somente em suas áreas e volume de poros) para esses materiais comparados às três biomassas analisadas.

A estrutura porosa dos biossorventes também foi analisada por microscopia eletrônica de varredura (MEV) antes e após os ensaios de biossorção em batelada. A 
Figura 2 apresenta as imagens de MEV das biomassas in natura e das amostras obtidas após o ensaio de adsorção, com íons de urânio adsorvidos. As imagens são apresentadas com ampliações de 1000x para os três materiais.

Figura 2 - Imagens de MEV obtidas para (a) casca de banana in natura, (b) casca de banana após ensaio de biossorção, (c) borra de café in natura, (d) borra de café após ensaio de biossorção, (e) semente de moringa in natura e (f) semente de moringa após ensaio de biossorção

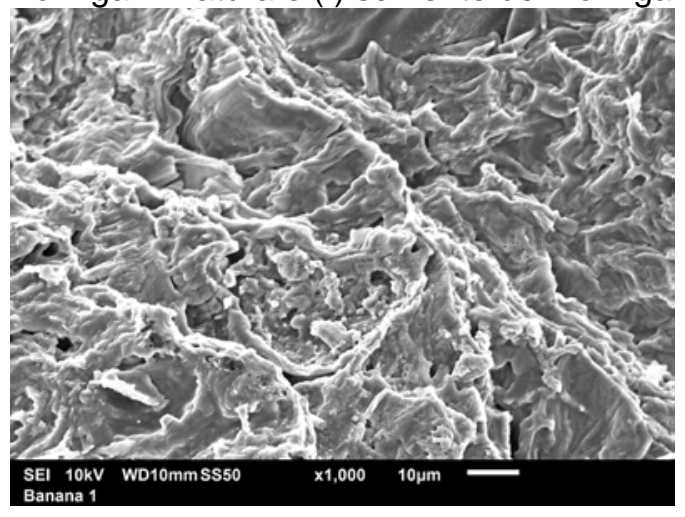

(a)

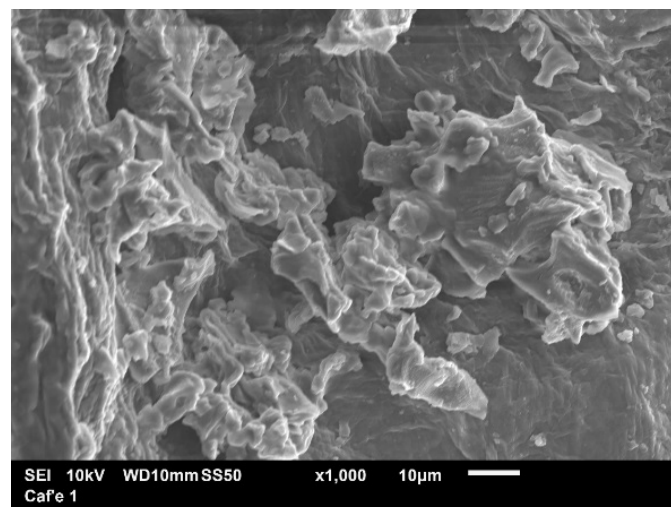

(c)

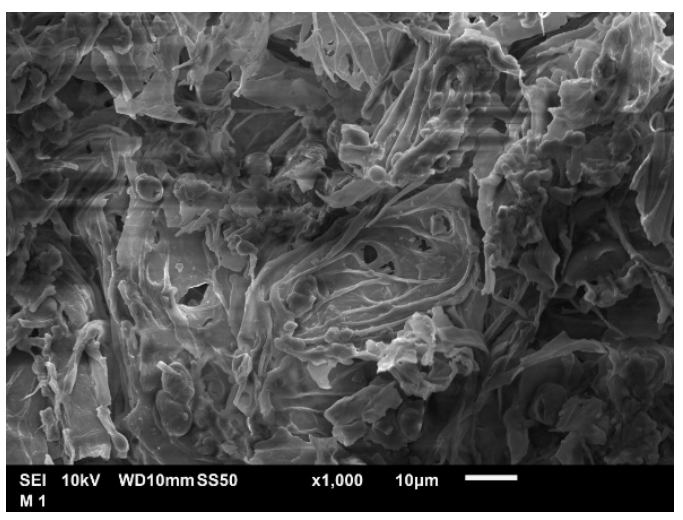

(e)

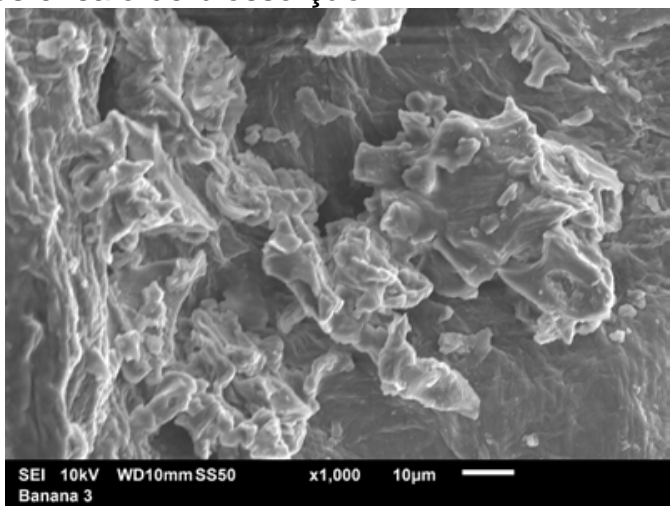

(b)

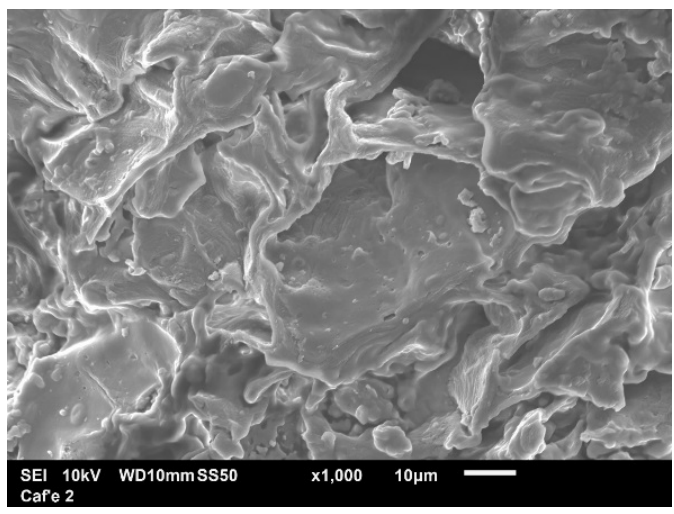

(d)

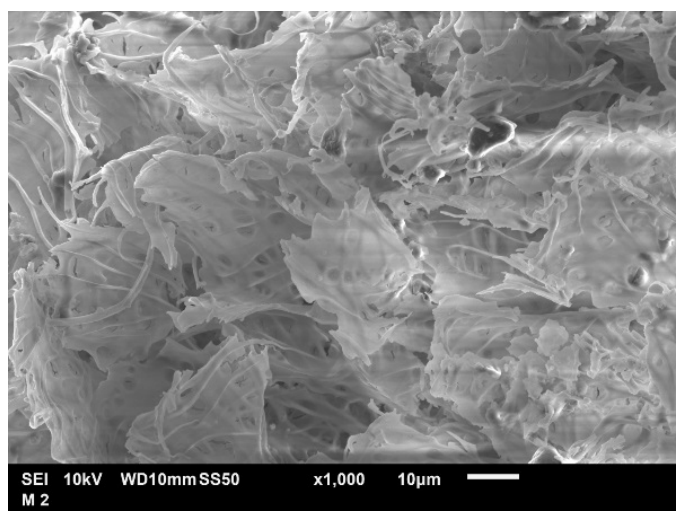

(f) 
Ao observar as micrografias obtidas, percebe-se a natureza irregular e porosa destes materiais, característica fundamental e desejada em estudos de biossorção. Notase também que as sementes de moringa apresentam maior irregularidade de superficie quando comparadas às demais biomassas em avaliação, exibindo maior quantidade de ramificações e poros, o que pode favorecer o ancoramento de adsorbatos em estudos de biossorção. A partir da análise visual das imagens obtidas, observa-se que as superfícies não sofreram alterações antes e após os ensaios em batelada.

Com a amplitude avaliada não foi possível visualizar o urânio adsorvido na superfície. No entanto, a adsorção de urânio foi comprovada pelos espectros obtidos por Espectrometria por Dispersão de Energia (EDS) apresentados na Tabela 4, na qual estão apresentados os resultados em porcentagem de composição em massa e em número de átomos para as cascas de banana, semente de moringa e borra de café antes $(A)$ e após (B) o ensaio de biossorção em batelada. As concentrações de carbono e oxigênio para todas as biomassas é característica de composição lignocelulósica destes tipos de materiais. Os grupos carboxílicos, hidroxilas e fenólicos provavelmente são os grupos funcionais capazes de adsorver metais ${ }^{35}$. A presença do potássio é inerente à casca de banana.

Como apresentado na Tabela 4, foi observada a presença de urânio na amostra após o ensaio de biossorção em batelada, o que confirma a remoção deste elemento das soluções utilizadas nos experimentos. A fim de corroborar ainda mais os resultados apresentados acima, a Tabela 5 apresenta os valores das concentrações iniciais e finais de urânio $\left(\mathrm{C}_{0}\right.$ e $\mathrm{C}_{\mathrm{f}}$, em $\left.\mathrm{mg} \mathrm{L}^{-1}\right)$ nas amostras 1, 2 e 3 de efluentes de drenagem ácida. $A$ concentração final de urânio foi obtida após os ensaios em batelada para os três biossorventes abordados neste trabalho e a partir disso, a eficiência de remoção foi calculada. Não houve ajuste do pH da amostra para os testes mencionados. 
Tabela 4 - Dados obtidos do EDS para o biossorvente casca de banana, semente de moringa e borra de café antes $(A)$ e após $(B)$ o ensaio em batelada

\begin{tabular}{|c|c|c|c|c|c|}
\hline Biossorvente & Elemento & $\begin{array}{c}\text { Massa A } \\
(\%)\end{array}$ & $\begin{array}{c}\mathrm{N}^{\circ} \text { de átomos } \\
\mathrm{A}(\%)\end{array}$ & $\begin{array}{c}\text { Massa } \\
\text { B (\%) }\end{array}$ & $\begin{array}{c}\mathrm{N}^{\circ} \text { de átomos } \\
\mathrm{B}(\%)\end{array}$ \\
\hline \multirow{8}{*}{ 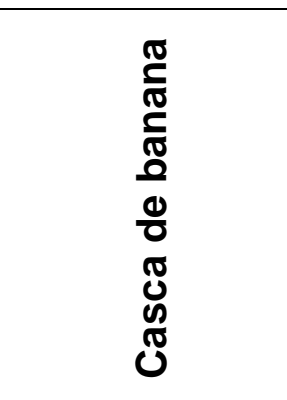 } & $C$ & 48,99 & 71,82 & 60,40 & 79,73 \\
\hline & $\mathrm{O}$ & 18,50 & 20,36 & 18,58 & 18,41 \\
\hline & $\mathrm{Al}$ & 0,22 & 0,15 & 0,33 & 0,19 \\
\hline & $\mathrm{Cl}$ & 4,12 & 2,05 & --- & --- \\
\hline & $\mathrm{K}$ & 8,63 & 3,88 & --- & --- \\
\hline & $\mathrm{U}$ & --- & --- & 0,12 & 1,66 \\
\hline & $A u^{*}$ & 19,53 & 1,75 & 20,57 & 0,01 \\
\hline & Total & 100 & 100 & 100 & 100 \\
\hline \multirow{7}{*}{ 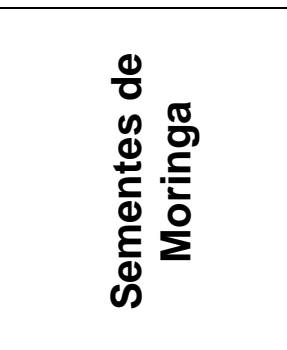 } & $\mathrm{C}$ & 57,22 & 81,55 & 68,60 & 79,69 \\
\hline & $\mathrm{O}$ & 14,20 & 15,19 & 22,27 & 19,43 \\
\hline & $\mathrm{Al}$ & 0,22 & 0,14 & 0,53 & 0,27 \\
\hline & $\mathrm{K}$ & 1,85 & 0,81 & --- & --- \\
\hline & $U$ & --- & --- & 0,13 & 0,01 \\
\hline & $A u^{\star}$ & 26,51 & 2,30 & 8,47 & 0,60 \\
\hline & Total & 100 & 100 & 100 & 100 \\
\hline \multirow{7}{*}{ 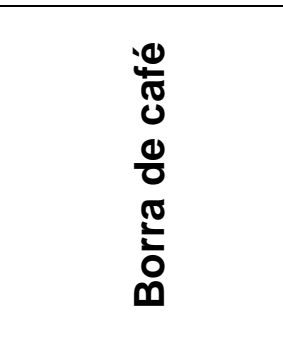 } & C & 63,79 & 81,36 & 65,13 & 79,72 \\
\hline & $\mathrm{O}$ & 17,95 & 17,19 & 20,94 & 19,24 \\
\hline & $\mathrm{Ca}$ & 0,10 & 0,04 & -- & --- \\
\hline & $\mathrm{Pb}$ & 0,47 & 0,03 & --- & --- \\
\hline & $\mathrm{U}$ & --- & --- & 0,19 & 0,01 \\
\hline & $\mathrm{Au} *$ & 17,69 & 1,38 & 13,74 & 1,03 \\
\hline & Total & 100 & 100 & 100 & 100 \\
\hline
\end{tabular}

${ }^{\star} A u$ = proveniente da metalização da amostra para ensaio.

Tabela 5 - Valores de concentração inicial $\left(C_{0}\right)$, concentração final $\left(C_{f}\right)$ e eficiência de remoção de urânio calculados para os biossorventes em estudo

\begin{tabular}{|c|c|c|c|}
\hline & $\mathrm{C}_{0}\left(\mathrm{mg} \mathrm{L}^{-1}\right)$ & $\mathrm{C}_{\mathrm{f}}\left(\mathrm{mg} \mathrm{L}^{-1}\right)$ & $E(\%)$ \\
\hline Amostra 1 & 5,971 & 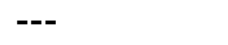 & --- \\
\hline Amostra 2 & 6,132 & --- & --- \\
\hline Amostra 3 & 5,762 & --- & --- \\
\hline Cascas de banana 1 & --- & 2,956 & 50,1 \\
\hline Cascas de banana 2 & --- & 2,477 & 59,6 \\
\hline Cascas de banana 3 & --- & 2,437 & 57,7 \\
\hline Borra de café 1 & --- & 1,583 & 73,5 \\
\hline Borra de café 2 & --- & 1,737 & 71,6 \\
\hline Borra de café 2 & --- & 1,382 & 76,0 \\
\hline $\begin{array}{l}\text { Sementes de } \\
\text { moringa } 1\end{array}$ & --- & 0,856 & 85,7 \\
\hline $\begin{array}{l}\text { Sementes de } \\
\text { moringa } 2\end{array}$ & --- & 0,777 & 87,3 \\
\hline $\begin{array}{l}\text { Sementes de } \\
\text { moringa } 3\end{array}$ & --- & 0,777 & 86,5 \\
\hline
\end{tabular}


A partir da análise dos resultados da Tabela 5, observou-se que as cascas de banana apresentaram valores de remoção médios em torno de $56 \%$, a borra de café exibiu significativo aumento com valor médio próximo a $74 \%$ e as sementes de moringa destacaram-se nos ensaios com valores de porcentagem de remoção em torno de 87 \%. Uma investigação mais detalhada do desempenho das biomassas em relação à remoção de urânio foi descrita anteriormente, onde houve a comparação dos dados experimentais com isotermas de adsorção ${ }^{34}$.

Correlacionando os resultados de adsorção com os parâmetros físicos das biomassas, observa-se que capacidade de adsorção é diretamente influenciada pela área superficial BET $\left(S_{p}\right)$ e o volume de poros $\left(V_{p}\right)$. De acordo com os resultados, a biomassa que apresenta maior remoção de urânio, apresenta maior área superficial e também maior volume de poros (87 \% de remoção de urânio, $S_{p}$ igual a $0,555 \mathrm{~m}^{2} \mathrm{~g}^{-1}$ e $V_{\mathrm{p}} 1,48 \times 10^{-3} \mathrm{~cm}^{3}$ $\mathrm{g}^{-1}$ ). Coerentemente, a ordem de maior eficiência é maior para a borra de café do que para a casca de banana.

Considerando os resultados obtidos, conclui-se que, dentre as três biomassas estudadas, a moringa é o biossorvente que apresenta maior potencial para ser aplicado na remoção de urânio em efluentes de drenagem ácida de minas neste intervalo de concentração. Entretanto, dependendo da disponibilidade dos resíduos avaliados e a logística para emprego dos mesmos nos processos de tratamento de água residuária, a utilização das outras biomassas permanece sendo de grande interessante econômico e ambiental, principalmente em relação à borra de café, que apresenta remoção de 74 \%. Além disso, esses materiais podem ser empregados em diferentes tratamentos prévios de biossorção. Os promissores resultados apresentados acima são ainda mais importantes visto que, na literatura os resultados para remoção de urânio empregando essas biomassas como adsorventes ainda são escassos, pois os dados de adsorção para as biomassas analisadas são feitos em sua maioria com cádmio e chumbo ${ }^{36-41}$.

\section{CONCLUSÕES}

O potencial de aplicação das biomassas casca de banana, sementes de moringa e borra de café para a remoção de urânio por biossorção em águas residuárias foi investigado e apresentaram resultados extremamente satisfatórios, apontando que o estudo de tais biomassas naturais apresentam inúmeras possibilidades de utilização, como por exemplo, para tratamento de efluentes, remediação de áreas afetadas e outras 
iniciativas tecnológicas que podem ser desenvolvidas, motivadas também pelo baixo custo desses biossorventes

Após a caracterização física das três biomassas, observou-se que a semente de moringa apresenta maior potencial de remoção devido à sua maior área superficial $(0,555$ $\left.\mathrm{m}^{2} \mathrm{~g}^{-1}\right)$ e volume de poros $\left(1,48 \times 10^{-3} \mathrm{~cm}^{3} \mathrm{~g}^{-1}\right)$. Em amostras de efluente com concentrações de urânio na ordem de $6 \mathrm{mg} \mathrm{L}^{-1}$, as sementes de moringa apresentaram-se como o biossorvente com melhor de remoção ( 87\%) quando comparadas as cascas de banana $(-56 \%)$ e borra de café ( $74 \%)$. Pelo exposto, sugere-se como melhor biossorvente de urânio proveniente da drenagem ácida as sementes de moringa. Entretanto, dependendo da disponibilidade dos resíduos avaliados e a logística para emprego dos mesmos nos processos de tratamento de água residuária, a utilização das outras duas biomassas permanece sendo de grande interessante econômico e ambiental, principalmente em relação à borra de café, que apresentou remoção de 74 \%.

\section{AGRADECIMENTOS}

Os autores agradecem à Fundação de Amparo à Pesquisa do Estado de São Paulo (FAPESP, Proc. 2015/06246-7) e ao Conselho Nacional de Desenvolvimento Científico e Tecnológico (CNPq, Proc. 400034/2016-6), pela concessão de auxílio financeiro"

\section{REFERÊNCIAS}

1. TORKABAD, M. G.; KESHTKAR, A. R.; SAFDARI, S. J. Comparison of polyethersulfone and polyamide nanofiltration membranes for uranium removal from aqueous solution. Prog. Nucl. Energ., v. 94, p. 93-100, 2017.

2. NAEEM, H.; BHATTI, H. N.; SADAF, S.; IQBAL, M.; Uranium remediation using modified Vigna radiata waste biomass. Appl. Radiat. Isotopes, v. 123, p. 94-101, 2017.

3. FAGUNDES, J. R. T; LEITE, A. L.; MELLO, C. E. F.; GOMES, R. C. Balanço Hídrico do Botafora BF4 da Mina de Urânio Osamu Utsumi, como Subsídio para Projetos de Remediação de Drenagem Ácida. RBRH, v. 13, n. 1, p. 19-28, 2008.

4. ABDULLAH, M.A.; PRASAD, A. G. D. Biosorption of nickel(II) from aqueous solutions and electroplanting wastewater using tamarind (Tamarindus indica L.). J. Basic Appl. Sci., v. 4, p. 3591-3601, 2010.

5. AZOUAOUA, N.; SADAOUIA, Z.; DJAAFRI, A.; MOKADDEMA, H. Adsorption of cadmium from aqueous solution onto untreated coffee grounds: equilibrium, kinetics and thermodynamics. $\mathbf{J}$. Hazard Mater., v. 184, n. 1-3, p. 126-134, 2010. 
6. KHELIFI, E.; TOUHAMI, Y.; BOUALLAGUI, H.; HAMDI, M. Biosorption of indigo from aqueous solution by dead fungal biomass Aspergillus alliaceus. Desalination Water Treat., v. 53, n. 4, p. 976-984, 2013.

7. MEKARZIA, A.; NAMANE, A.; BENRACHEDI, N. Chemical production and characterization of activated carbon from waste 'coffee grounds'. Int. J. Environ. Waste Manag., v. 12, n. 2, p. 154166, 2013.

8. OLIVEIRA, L.S.; FRANCA, A. S.; ALVES, T. M.; ROCHA, S. D. F. Evaluation of untreated coffee husks as potential biosorbents for treatment of dye contaminated waters. J. Hazard Mater., v. 155, n. 3, p. 507-512, 2008.

9. RAFATULLAH, M.; SULAIMAN, O.; HASHIM, R.; AHMAD, A. Adsorption of methylene blue on low-cost adsorbents: a review. J. Hazard Mater., v. 177, p. 70-80, 2010.

10. BRANCA, C.; DI BLASI, C. A lumped kinetic model for banana peel combustion. Thermochim. Acta,v. 614, p. 68-75, 2015.

11. ZHOU, N.; CHEN, H.; XI, J.; YAO, D.; ZHOU, Z.; TIAN, Y.; LU, X. Biochars with excellent Pb(II) adsorption property produced from fresh and dehydrated banana peels via hydrothermal carbonization. Bioresource Technol., v. 232, p. 204-210, 2017.

12. JANG, H.; OCON, J. D.; LEE, S.; LEE, J. K.; LEE, J. Direct power generation from waste coffee grounds in a biomass fuel cell. J. Power Sources, v. 296, p. 433-439, 2015.

13. KIM, J.; KIM. H.; BAEK, G.; LEE, C. Anaerobic co-digestion of spent coffee grounds with different waste feedstocks for biogas production. Waste Manage, v. 60, p. 322-328, 2017.

14. GETACHEW, A. T.; CHUN, B. S. Influence of pretreatment and modifiers on subcritical water liquefaction of spent coffee grounds: A green waste valorization approach. J. Clean. Prod., v. 142, p. 3719-3727, 2017.

15. ZEIN, S. H.; GYAMERA, B. A.; SKOULOU, V. K. Nanocarbons from acid pretreated Waste Coffee Grounds using microwave radiation. Mater. Lett., v. 193, p. 46-49, 2017.

16. ANASTOPOULOS, I.; KARAMESOUTI, M.; MITROPOULOS, A. C.; KYZAS, G. Z. "A review for coffee adsorbents". J. Mol. Liq., v. 229, p. 555-565, 2017.

17. BOONAMNUAYVITAYA, V.; CHAIYA, C.; TANTHAPANICHAKOON, W.; JARUDILOKKUL, S. Removal of heavy metals by adsorbent prepared from pyrolyzed coffee residues and clay. Sep. Purif. Technol., v. 35, n. 1, p. 11-22, 2004.

18. KIM, M. MIN, H. G.; KOO, M.; PARK, J.; LEE, S. H.; BAK, G. I.; KIM, J. G. The effectiveness of spent coffee grounds and its biochar on the amelioration of heavy metals-contaminated water and soil using chemical and biological assessments. J. Environ. Manage., v. 146, p. 124-130, 2014.

19. KYZAS, G. Z.; LAZARIDIS, N. K.; MITROPOULOS, CH, A. Removal of dyes from aqueous solutions with untreated coffee residues as potential low-cost adsorbents: Equilibrium, reuse and thermodynamic approach. Chem. Eng. J., v. 189-190, p. 148-159, 2012.

20. AL-ANIZI, A. A.; HELLYER, M. T.; ZHANG, D. Toxicity assessment and modelling of Moringa oleifera seeds in water purification by whole cell bioreporter. Water Res., v. 56, p. 77-87, 2014. 
21. ANUDEEP, S.; PRASANNA, V.K.; ADYAA, S. M.; RADHA, C. Characterization of soluble dietary fiber from Moringa oleifera seeds and its immunomodulatory effects. Int. J. Biol. Macromol., v. 91, p. 656-662, 2016.

22. CAMACHO, F. P.; SOUSA, V. S.; BERGAMASCO, R.; TEIXEIRA, M. R. The use of Moringa oleifera as a natural coagulant in surface water treatment. Chem. Eng. J., v. 313, p. 226-237, 2017.

23. BAPTISTA, A. T. A.; SILVA, M. O.; GOMES, R. G.; BERGAMASCO, R.; VIEIRA, M. F.; VIEIRA, A. M. S. Protein fractionation of seeds of Moringa oleifera lam and its application in superficial water treatment. Sep. Purif. Technol., v. 180, p. 114-124, 2017.

24. ARAÚJO, C. S. T; ALVES, V. N.; REZENDE, H. C.; COELHO, N. M. M. Development of a flow system for the determination of low concentrations of silver using Moringa oleifera seeds as biosorbent and flame atomic absorption spectrometry, Microchem. J., v. 96, p. 82-85, 2010.

25. BONIOLO, M. R.; MONTEIRO, R. A.; YAMAURA, M. Biomassa residual para remoção de íons uranilo. Quim. Nova, v. 33, n. 3, p. 547-551, 2010.

26. ROWELL, R. M.; HAN, J. S.; ROWELL, J. S. Characterization and Factors Affecting Fiber Properties. In: FROLLINI, E.; LEÃ̃, A. L.; MATTOSO, L. H. C. (Orgs.) Natural Polymers and Agrofibers Based Composites. São Carlos: Embrapa Instrumentação Agropecuária, 2000. p. 115-134.

27. YANG, H.; YAN, R.; CHEN, H.; LEE, D. H.; ZHENG, C. Characteristics of hemicelluloses, cellulose and lignin pyrolysis. Fuel, v. 86, p. 1781-1788, 2007.

28. FANG, X.; JIA, L.; YIN, L. A weighted average global process model based on two-stage kinetic scheme for biomass combustion. Biomass Bioenerg, v. 48, p. 43-45, 2013.

29. KHATAMI, R.; STIVERS, C.; JOSHI, K.; LEVENDIS, Y. A.; SAROFIM, A. F. Combustion behavior of single particles from three different coal ranks and from sugar cane bagasse in $\mathrm{O}_{2} / \mathrm{N}_{2}$ and $\mathrm{O}_{2} / \mathrm{CO}_{2}$ atmospheres. Combust Flame, v. 159, p. 1253-1271, 2012.

30. MUNIR, S.; DAOOD, S.S.; NIMMO, W.; CUNLIFFE, A.M. GIBBS, B.M. Thermal analysis and devolatilization kinetics of cotton stalk, sugar cane bagasse and shea meal under nitrogen and air atmospheres. Bioresource Technol, v. 100, p. 1413-1418, 2009.

31. RAMAJO-ESCALERA, B.; ESPINA, A.; GARCÍA, J. R.; SOSA-ARNAO, J. H.; NEBRA, S. A. Model-free kinetics applied to sugarcane bagasse combustion. Thermochim. Acta, v. 448, p. 111116, 2006.

32. WANG, Q.; ZHAO, W.; LIU, H.; JIA, C.; XU, H. Reactivity and kinetic analysis of biomass during combustion.Energy Procedia, v. 17, p. 869-875, 2012.33. RAZERA, I. A. T. Fibras lignocelulósicas como agente de reforço de compósitos de matriz fenólica e lignofenólica. 2006. 189 f. Tese (Doutorado em Química) - Instituto de Química de São Carlos, Universidade de São Paulo, São Carlos, 2006.

34. GARCIA, M. L.; BONIOLO, M. R.; MENEGÁRIO, A. A. Moringa Seed, Residual Coffee Powder, and Banana Peel as Biosorbents for Uranium Removal from Acid Mine Drainage. IJERA, v. 7, n. 3, p. 60-68, 2017.

35. DÁVILA-GUZMÁN, N. E.; CERINO-CORDOVA, F. J.; SOTO-REGALADO, E.; RANGELMENDEZ, J. R.; DÍAZ-FLORES, P. E.; GARZA-GONZALEZ, M. T.; LOREDO-MEDRANO, J. A. 
Copper biosorption by spent coffee ground: Equilibrium, Kinetics and Mechanism. Clean-Soil, Air, Water, v. 41, p. 557-564, 2013.

36. ANWAR, J.; SHAFIQUE, U.; ZAMAN, W.; SALMAN, M.; DAR, A.; ANWAR, S. Removal of $\mathrm{Pb}$ (II) and $\mathrm{Cd}(\mathrm{II})$ from water by adsorption on peels of banana. Bioresource Technol, v. 101, $\mathrm{p}$. 1752-1755, 2010.

37. MEMON, J. R.; MEMON, S.Q.; BHANGER, M.I.; MEMON, G.Z.; EL-TURKI, A.; HALLAM, K.R.; ALLENC, G.C. Characterization of banana peel by scanning electron microscopy and FT-IR spectroscopy and its use for cadmium removal. Colloid Surface B , v. 66, p. 260-265, 2008.

38. SAUMYA, P.; DEEPA, B.; ABRAHAM, E.; GIRIJA, N.; GEETHA, P.; JACOB, L.; KOSHY, M. Biosorption of $\mathrm{Cd}(\mathrm{II})$ from aqueous solution using xanthated nano banana cellulose: Equilibrium and kinetic studies. Ecotox Environ Safe , v. 98, p. 352-360, 2013.

39. AZOUAOUA, N.; SADAOUIA, Z.; DJAAFRI, A.; MOKADDEMA, H. Adsorption of cadmium from aqueous solution onto untreated coffee grounds: Equilibrium, kinetics and thermodynamics. J. Hazard Mater. , v. 184, p. 126-134, 2010.

40. OLIVEIRA, L. S.; FRANCA, A. S.; ALVES, T. M.; ROCHA, S. D. F. Evaluation of untreated coffee husks as potential biosorbents for treatment of dye contaminated waters. J. Hazard Mater., v. 156, p. $507-512.2008$.

41. MENEGHEL, A,P.; GONÇALVES, A.C.; RUBIO, F.; DRAGUNSKI, D. C.; LINDINO, C.A.; STREY, L. Biosorption of Cadmium from Water Using Moringa (Moringa oleifera Lam.) Seeds. Water Air Soil Poll, v. 224, p. 1383-1387, 2013. 